\title{
A new Discidae subgenus and two new species (Gastropoda: Pulmonata) from the Canary Islands
}

\author{
YURENA YANES ${ }^{1}$, GERALDINE A. HOLYOAK ${ }^{2}$, DAVID T. HOLYOAK ${ }^{2}$, \\ MARIA R. ALONSO ${ }^{3} \&$ MIGUEL IBÁÑEZ ${ }^{4}$ \\ ${ }^{1}$ Instituto Andaluz de Ciencias de la Tierra (CSIC-Universidad de Granada), Camino del Jueves s/n, 18100, Armilla, Granada, Spain. \\ E-mail:yurenayanes@ugr.es \\ ${ }^{2}$ Quinta da Cachopa, Barcoila, 6100-014 Cabeçudo, Portugal.E-mail: holyoak9187@hotmail.com \\ ${ }^{3}$ Departamento de Biologia Animal, Universidad de La Laguna, E-38206 La Laguna, Tenerife, Islas Canarias, Spain. \\ E-mail: malonso@ull.es \\ ${ }^{4}$ Corresponding author. Departamento de Biologia Animal, Universidad de La Laguna, E-38206 La Laguna, Tenerife, Islas Canarias, \\ Spain.E-mail:mibanez@ull.es
}

The family Discidae has undergone extensive speciation in the Macaronesian region (eastern Atlantic Ocean), with 11 endemic species recognised from Madeira and the Canary Islands in recent checklists (Bank, Groh \& Ripken 2002; Seddon 2008; Fauna Europaea database project 2011), grouped into the genera Keraea Gude, 1911 and Discus Fitzinger, 1833: K. deflorata (R.T. Lowe, 1855) and D. (Atlantica) guerinianus (R.T. Lowe, 1852), from Madeira; and nine species from the Canary Islands: K. garachicoensis (Wollaston, 1878), D. scutula, (Shuttleworth, 1852), D. engonatus (Shuttleworth, 1852), D. textilis (Shuttleworth, 1852), D. retextus, (Shuttleworth, 1852), D. putrescens (R.T. Lowe, 1861), D. ganodus (J. Mabille, 1882), D. gomerensis Rähle, 1994, and D. kompsus (J. Mabille, 1883). In contrast with the anatomical data known for the European and North American genera Discus and Anguispira Morse, 1864 (Uminski 1962; Pilsbry 1948), there has hitherto been no information published on the internal anatomy of the Canary Islands and Madeiran species, which are known only by their shell characters. In this paper we raise Atlantica to the rank of genus in the Discidae and describe shell and anatomical characters for two new species from La Gomera and Tenerife, respectively. They are grouped in a new subgenus of Atlantica, largely restricted to the laurisilva. This laurel-rich forest occurs in humid subtropical and warm-temperate regions with little variability in temperatures and is developed between 600 and 1,200 m above sea level in the Canary Islands (Yanes et al. 2009b: Fig. 2).

The snails were drowned in water and fixed in $80 \%$ ethanol. The methodology was described in Kerney \& Cameron (1979) and Yanes et al. (2009a). "Proximal" and "distal" refer to the position in relation to the ovotestis. Comparisons have been made with photographs of syntypes of Patula garachicoensis Wollaston, 1878, Helix putrescens R.T. Lowe, 1861, the Discidae species described by Shuttleworth (1852) from the Canary Islands (Neubert \& Gosteli 2003), a possible syntype of $H$. gueriniana R.T. Lowe, 1852, a shell of $H$. calathoides R.T. Lowe, 1863 and the shell drawings (Rähle 1994) of the holotype of D. gomerensis.

Institutional and other abbreviations

AIT Alonso and Ibáñez collection, Department of Animal Biology, University of La Laguna, Tenerife, Canary Islands, Spain

JSGC J. Santana private collection, Las Palmas de Gran Canaria, Spain

TFMC Museo de Ciencias Naturales de Tenerife, Canary Islands, Spain

UTM Universal Transverse Mercator cartographic projection system 


\section{Genus Atlantica Ancey, 1887}

Atlantica (Canaridiscus) Alonso \& Ibáñez, n. subgen.

Type species: Atlantica saproxylophaga $\mathbf{\text { sp. nov. }}$

Diagnosis.Shell depressed, without tooth-shaped lamellae on the inside of the body whorl. Penis long to very long; penial retractor muscle inserted near the penis/vas deferens junction: there is no epiphallus and flagellum, as in the other Discidae; bursa copulatrix small; bursa duct long, thin, without diverticulum; albumen gland short; hermaphrodite duct very long.

\section{Atlantica (Canaridiscus) saproxylophaga Alonso, G. Holyoak \& Yanes, sp. nov.}

Type locality. Montaña Quemada, La Gomera. UTM: 28RBS8312, $1000 \mathrm{~m}$ altitude.

Holotype (alcohol specimen): TFMC (MT 0426). Leg. M. Ibáñez, 20 December 1992.

Paratypes. 6 alcohol specimens (AIT) and 5 shells (JSGC), collected between 1983 and 2008 from the Park National of Garajonay (La Gomera).

Etymology. The specific epithet refers to the specimens being found only inside the damp trunks of decaying trees in the laurel forest (laurisilva).

Distribution (Fig. 1). Endemic to La Gomera. It occurs at an altitude of 740-1150 m, in the National Park of Garajonay.

Description. Shell large (Fig. 2 A), fragile, lens shaped, slightly translucent, with numerous scars on the dorsal side, with $6 \frac{1}{2}-7$ irregularly convex whorls (almost flat), keeled up to the aperture, slowly and regularly increasing in size; sutures impressed; base excavated with a widely open umbilicus, which reaches nearly $30 \%$ of the shell maximum diameter and reveals all the whorls including the nucleus; aperture angular because of the keel, irregularly arched above, ovate below; peristome simple, acute, without parietal callus, parietal and columellar lip terminations widely separated. Shell colour brown, with irregular pale-brown patches above and below. Protoconch smooth, with 11/2-2 whorls. Teleoconch almost regularly ribbed above, with about 5 fine radial ribs $/ \mathrm{mm}$, smoother and regularly ribbed below. Some dorsal ribs are interrupted, forming small granulations on the early whorls.

Genital system (five specimens dissected). Right ommatophore retractor crosses the distal genital system through a ring formed by penis, vas deferens and vagina (Fig. 3 B-D), open proximally (Fig. 3 C), "bridle" linking the vas deferens to the proximal end of the genital atrium (Fig. 3 D, E). Atrium short (Fig. 3 C, D). Penis tubular, spectacularly long and with many folds in its natural resting position, occupying slightly more than one-half of the body whorl length (Fig. $3 \mathrm{~A}$ ), but reaching about $100 \mathrm{~mm}$ in length when extended (Fig. $3 \mathrm{C}$ ). Penis thickest in its proximal part, thinnest in the middle part and intermediate in the distal part; penial cavity occupied by two pilasters, a larger and a smaller (Fig. 3 C). Vas deferens enters the penis through a short and fine duct (Fig. 3 F), close to insertion of penial retractor muscle. Penial retractor long (more than $10 \mathrm{~mm}$ ), running close to columellar muscle pack (Fig. $3 \mathrm{~A}$ ) but shorter than the pack muscles and with single attachment to the visceral tegument (Fig. 3 B). Bursa copulatrix small, bursa duct long and very thin, without diverticulum (Fig. 3 C); Albumen gland very short, forked (Fig. $3 \mathrm{G}$ ). Hermaphroditic duct large, regularly kinked in the middle part, its distal part little folded and distended into an "ampulla" (Fig. 3 C, G); talon short, apparently lobed (Fig. 3 G). 


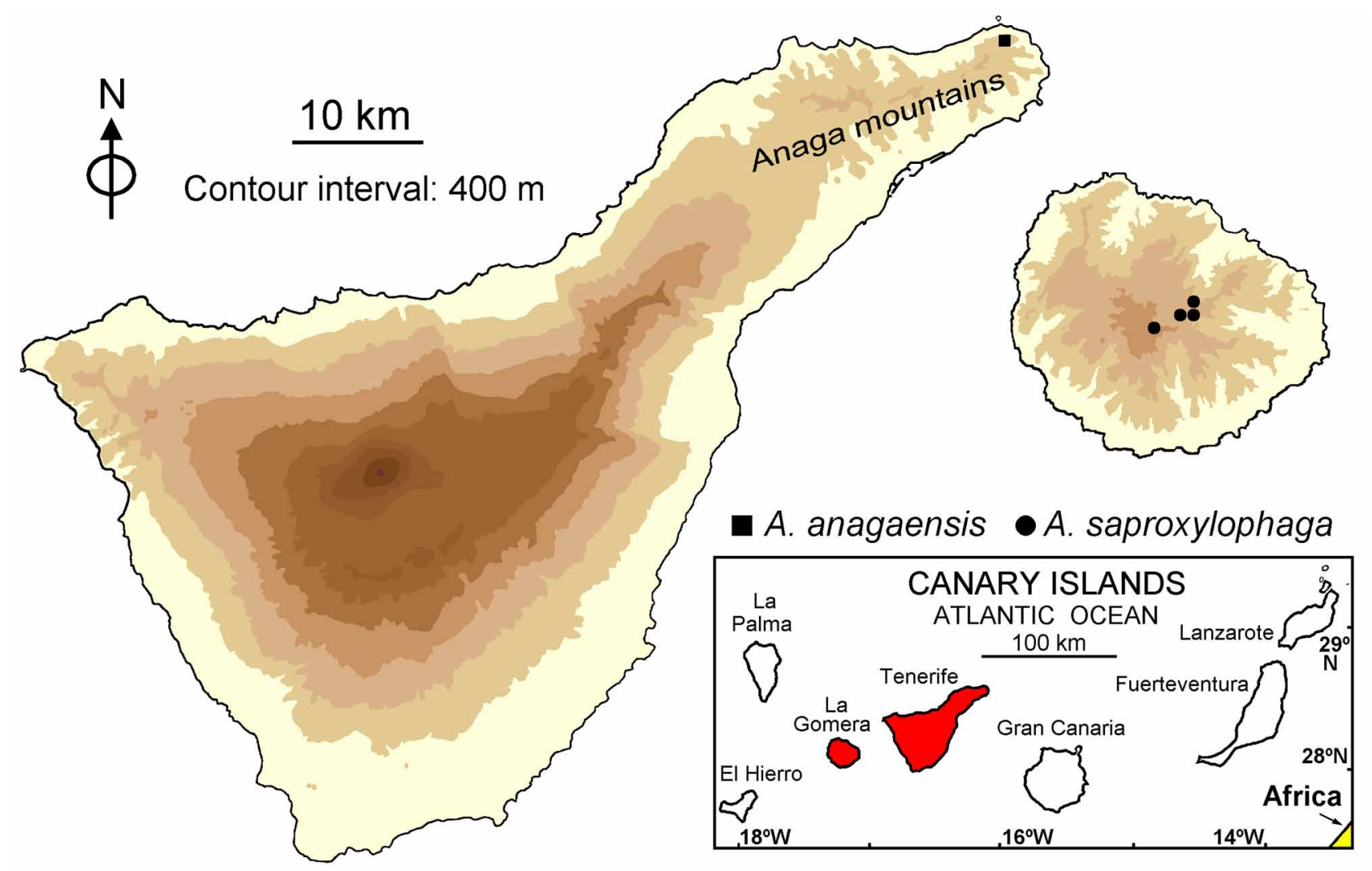

FIGURE 1. Geographical distribution of the new Atlantica (Canaridiscus) species.

\section{Atlantica (Canaridiscus) anagaensis Ibáñez \& D. Holyoak, sp. nov.}

Type locality. Montaña Tafada, Anaga, Tenerife. UTM: 28RCS8761, $650 \mathrm{~m}$ altitude.

Holotype (Fig. 3 E; shell). TFMC (MT 0427). Leg. M. Valido, 14 November 1987.

Paratypes. 8 alcohol specimens and 5 shells, collected at the type locality, deposited in AIT.

Etymology. The specific epithet derives from the Anaga mountains.

Distribution and habitat (Fig. 1). Endemic to Tenerife. It has been collected only at the type locality, in rotten trunks of tree heath Erica arborea Linnaeus.

Description. Shell small (Fig. 2 B), fragile, flattened, discoidal, with 53/4-61/4 uniformly convex whorls, regularly increasing in size, and deep sutures; base excavated with a widely open umbilicus, which reaches nearly onethird of the shell maximum diameter; aperture rounded, almost circular but slightly ovate in the columellar zone; peristome simple, acute, without parietal callus, parietal and columellar lip terminations widely separated. Shell colour brown with small pale-brown patches. Protoconch smooth, with about 13/4 whorls. Teleoconch regularly ribbed, with about 5 thick radial ribs/mm.

Genital system (Fig. 4 A-D; four specimens dissected). Atrium short. Distal genital system with a ring (Fig. 4 A), similar to that of A. saproxylophaga. Penis tubular, long and folded, occupying about one-half of the body whorl length (Fig. 4 A, B), but reaching about $45 \mathrm{~mm}$ in length when extended (Fig. 4 B). Penis thickest in its proximal part, intermediate in the middle part, and thinnest in the distal part; penial cavity occupied mainly by a thick pilaster, the penial cavity being small. Entrance to vas deferens close to insertion of penial retractor muscle. Wall of the proximal end of penis with an inner, apparently muscular thickening inside the point where the penial retractor muscle inserts on the outside (Fig. 4 D). Penial retractor long, running close to columellar muscle pack but shorter than the pack muscles and with single attachment to the visceral tegument. Bursa copulatrix small (Fig. 4 B); bursa duct long and very thin, without diverticulum. Hermaphroditic duct long, regularly kinked in the middle part (Figs 4 A, B). Albumen gland and talon short (Figs 4 A, C). 


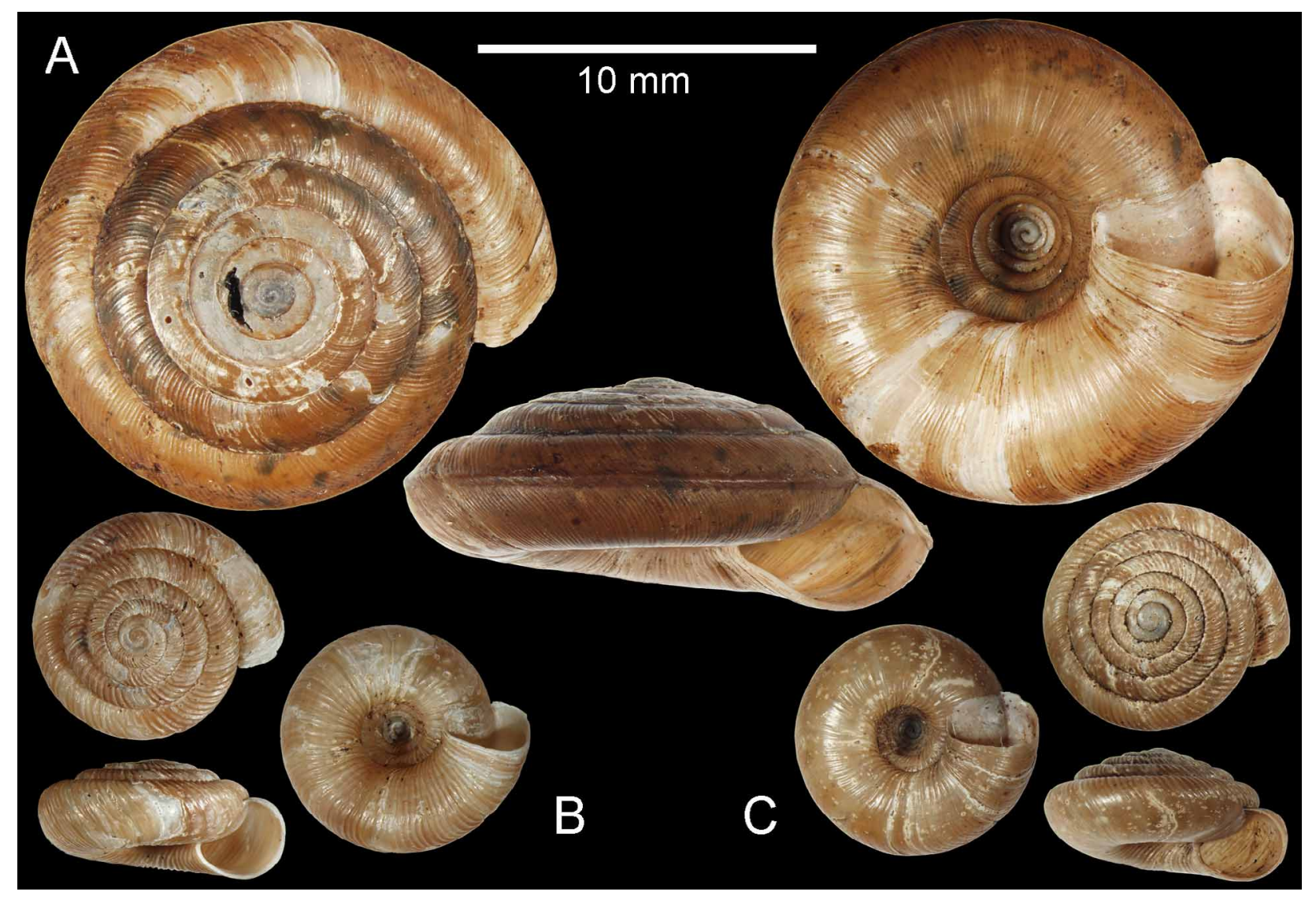

FIGURE 2. A, a paratype (JSGC) of Atlantica saproxylophaga sp. nov., from the Garajonay National Park (La Gomera); B, holotype of A. anagaensis sp. nov., from Tafada mountain (Anaga, Tenerife); C, a shell of Helix textilis Shuttleworth, 1852, from Marcos y Cordero, La Palma.

\section{Morphological comparisons and final remarks}

Shells: A. saproxylophaga sp. nov. has the largest shell of all the Discidae species known from Macaronesia, its maximum diameter being about one-third more than that of the next largest species, A. putrescens. The shell form, ornamentation and dimensions of A. anagaensis sp. nov. (Fig. 2 B) are similar to those of A. textilis (Fig. 2 C), from La Palma Island. However, the shell of A. anagaensis is flatter than that of A. textilis because the early whorls of the former are clearly smaller than those of $A$. textilis and the body whorl of A. textilis is slightly angular whereas that of A. anagaensis is more rounded.

Genital systems: The absence of an epiphallus was observed by Uminski (1962) in the two subgenera of Discus and by Solem (1976) in Anguispira. The connection between the vas deferens and the penis in A. (C.) saproxylophaga (Fig. 3 F) is similar to that described by Solem (1976) in Anguispira. Thus, the epiphallus apparently is not present in Atlantica either. The functioning of the penis in Atlantica requires further study. In A. saproxylophaga the penis is remarkably long, i.e. $c a$ eight times the maximum shell diameter. Consequently the pattern of mating with simultaneous intromission and internal sperm transfer usual in many pulmonate families seems unlikely to occur. Furthermore, the distal female genital tract in this species appears too small to accommodate more than part of the penis. Hence, observations are needed to ascertain whether sperm transfer occurs externally without intromission as in Limax and Deroceras, or with only partial intromission.

Generic classification and affinities of the Discidae genera: Due to the unknown anatomical and genetic characteristics of Atlantica gueriniana from Madeira (the type-species of Atlantica), the existence of close relationships between the Madeiran and Canary Islands Discidae can only be surmised. Nevertheless, they have generally similar shell characters as described above and both are largely restricted to the laurisilva of these archipelagos in northern Macaronesia, so we assume that they are closely related. Thus, we provisionally group all of the taxa in Atlantica, raising it to generic rank in the Discidae because it is not closely related to the genera Discus and Anguispira. The three genera share many shell and anatomical character-states of the Discidae, as follows: a shell moderately to strongly depressed, radially ribbed, with the base excavated with a widely open umbilicus that 


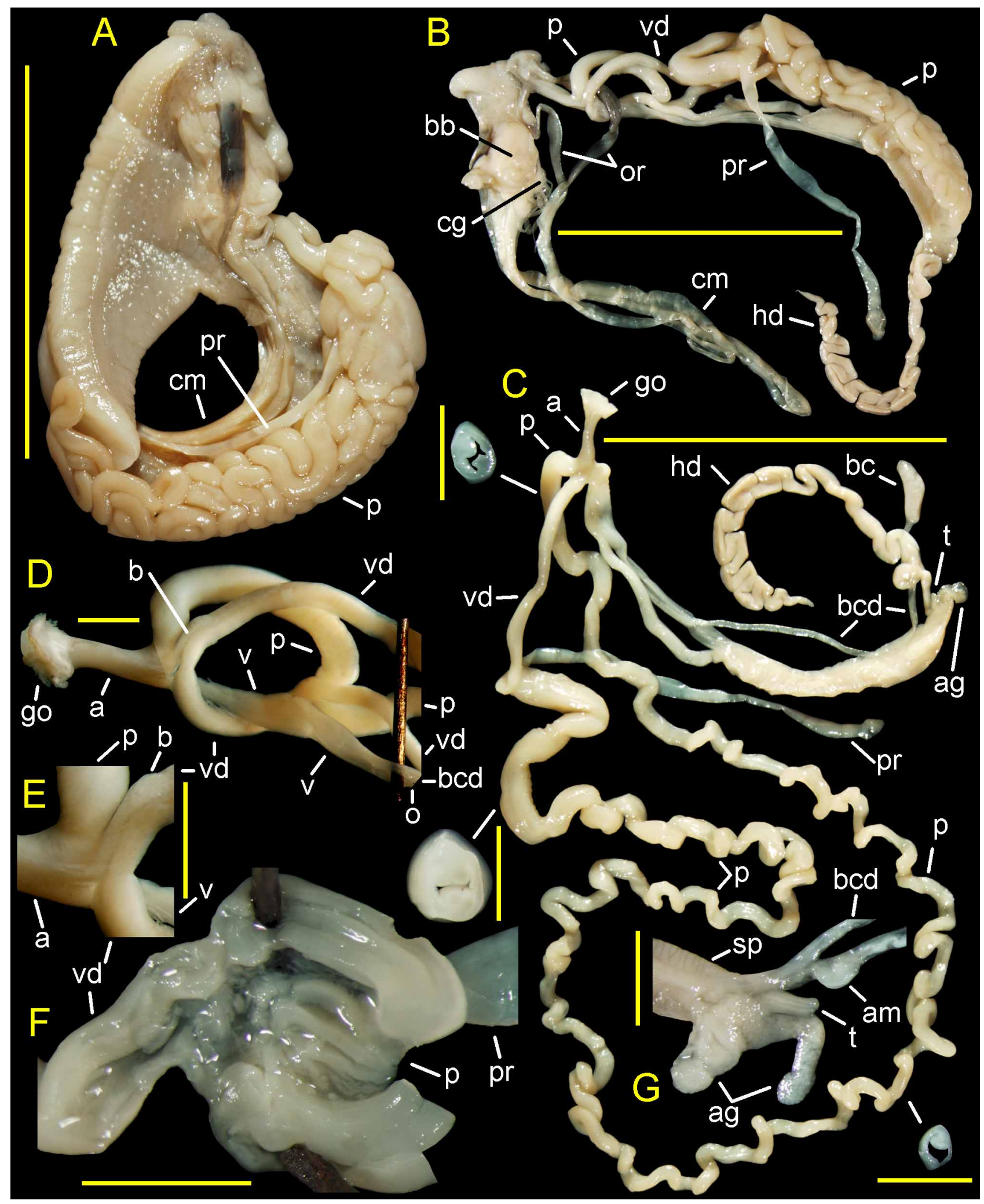

FIGURE 3. Atlantica (Canaridiscus) saproxylophaga sp. nov. A, snail at early stage of dissection (left side); B, relation between the genital system and the muscles of the columellar muscle pack, mainly the right ommatophore retractor; $\mathrm{C}$, genital system unfolded with three penis cross sections, proximal, intermediate and distal; D, E, details of the distal zone of the genital system; F, longitudinal section of the vas deferens-penis connection; G, detail of the albumen gland, talon and distal zone of the hermaphroditic duct with the "ampulla"; a, atrium; ag, albumen gland; am, ampulla; b, bridle between the atrium and the vas deferens; bb, buccal bulb; bc, bursa copulatrix; bcd, bursa copulatrix duct; cg, cerebral ganglia; cm, columellar muscle pack; go, genital orifice; hd, hermaphroditic duct; o, oviduct; or, ommatophore retractors; p, penis; pr, penis retractor; sp, spermoviduct; t, talon; v, vagina; vd, vas deferens. Scale bar of the figs A-C: $10 \mathrm{~mm}$; that of all the others, $1 \mathrm{~mm}$. 


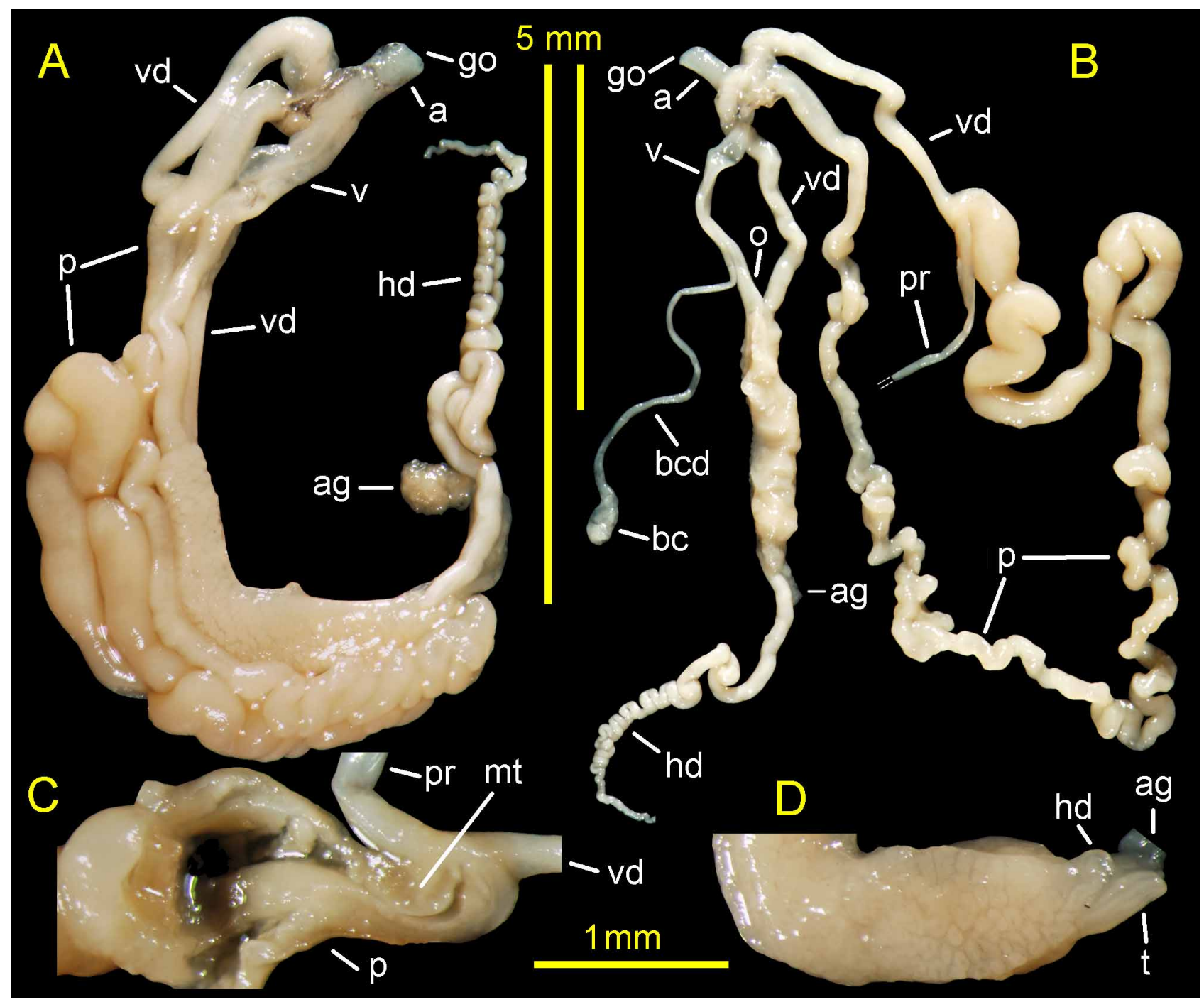

FIGURE 4. Atlantica (Canaridiscus) anagaensis sp. nov.; A, genital system in natural (folded) position; B, genital system unfolded; C, longitudinal section of the proximal end of penis, showing an inner, apparently muscular thickening in the point of the penial retractor muscle insertion; D, proximal part of the spermoviduct, and the talon; a, atrium; ag, albumen gland; bc, bursa copulatrix; bcd, bursa copulatrix duct; go, genital orifice; hd, hermaphroditic duct; mt, muscular thickening; o, oviduct; $p$, penis; pr, penis retractor; t, talon; v, vagina; vd, vas deferens.

reveals all the whorls including the nucleus; lung long and narrow, without large or noticeable branches on the pulmonary vein; kidney triangular, a little longer than the pericardium; secondary ureter closed; male genital system lacking flagellum and epiphallus; penis without penial papilla; bursa copulatrix small; bursa duct long and very thin, without diverticulum.

The genera Discus and Anguispira share similar characters of the genital system, notably a short penis, whereas Atlantica clearly differs from both of them because it has a much longer penis. Therefore the relationship of Atlantica with Discus and Anguispira is apparently more distant than that between the last two genera.

\section{Acknowledgements}

Special thanks go to Mr. Jesús Santana (JSGC) for the loan of paratype shells of A. saproxylophaga and some specimens of A. gomerensis. 


\section{References}

Bank, R.A., Groh, K. \& Ripken, T.E.J. (2002) Catalogue and bibliography of the non-marine Mollusca of Macaronesia. In: Falkner M., Groh K., Speight M.C.D., eds. Collectanea Malacologica —Festschrift für Gerhard Falkner. ConchBooks, Hackenheim, 89-235, pl. 14-26.

Fauna Europaea database project (2011) Version 2.4, last update, 27 January 2011; http://www.faunaeur.org/.

Kerney, M.P. \& Cameron, R.A.D. (1979) A field guide to the land snails of Britain and north-west Europe. Collins, London, 288 pp.

Neubert, E. \& Gosteli, M. (2003) The molluscan species described by Robert James Shuttleworth. I. Gastropoda: Pulmonata. Contributions to Natural History, 1, 1-123.

Pilsbry, H.A. (1948) Land Mollusca of North America (north of Mexico). Academy of Natural Sciences of Philadelphia, Philadelphia, Monograph 3, vol. II (2), i-xlvii, 521-1113.

Rähle, W. (1994) Über eine neue Discus-Art von La Gomera (Kanarische Inseln) (Gastropoda Pulmonata: Endodontidae). Basteria, 58, 11-14.

Seddon, M.B. (2008) The landsnails of Madeira. An illustrated compendium of the landsnails and slugs of the Madeiran archipelago. Studies in Biodiversity and Systematics of Terrestrial Organisms from the National Museum of Wales, Biotir Reports, 2, 1-204.

Solem, A. (1976) Species criteria in Anguispira (Anguispira) (Pulmonata: Discidae). The Nautilus, 90, 15-23.

Thiele, J. (1931) Handbuch der systematischen Weichtierkunde. Gastropoda: Opisthobranchia und Pulmonata. Gustav Fischer, Stuttgart, Erster Band, Zweiter Teil, 377-778.

Uminski, T. (1962) Revision of the Palearctic forms of the genus Discus Fitzinger, 1833 (Gastropoda, Endodontidae). Annales Zoologici Musei Polonici Historiae Naturalis, 20, 299-333.

Yanes, Y., Martín, J., Moro, L., Alonso, M.R. \& Ibáñez, M. (2009a) On the relationships of the genus Napaeus (Gastropoda: Pulmonata: Enidae), with the description of four new species from the Canary Islands. Journal of Natural History, 43, 21792207.

Yanes, Y., Romanek, C.S., Delgado, A., Brant, H.A., Noakes, J.E., Alonso, M.R. \& Ibáñez, M. (2009b) Oxygen and carbon stable isotopes of modern land snail shells as environmental indicators from a low latitude oceanic island. Geochimica et Cosmochimica Acta, 73, 4077-4099. 